\title{
LUZES E SOMBRAS NO DIA SOCIAL: O SÍMBOLO RIUUAL EM VICTOR TURNER*
}

\author{
Maria Laura Viveiros de Castro Cavalcanti \\ Universidade Federal do Rio de Janeiro - Brasil
}

Resumo: O tema do ritual é marcante na obra de Victor Turner, em especial nos trabalhos diretamente baseados em sua experiência de campo entre os lunda-ndembus realizada nos anos 1950. O artigo examina as formulações do autor nessa fase de sua obra, tomando como fio condutor o conceito de símbolo ritual, que condensa aspectos centrais da abordagem dos rituais. O conceito de símbolo ritual é examinado "em ação", ou seja, é enfocado através de diferentes textos e visto como um dos lugares da obra turneriana onde o esforço de teorização se associou à apreensão etnográfica dos sentidos do ritual. Com essa noção, ao articular reflexões sobre as dimensões cognitivas e experienciais da vida social, Turner buscou abranger dimensões inconscientes do pensamento e da ação. $O$ exame de sua hermenêutica do símbolo indica uma solução de compromisso entre duas direções de pensamento turneriano: a tendência metafísica e religiosa e sua aproximação de formulações psicanalíticas freudianas.

Palavras-chave: etnografia, ritual, símbolo ritual, Victor Turner.

Abstract: Ritual is one of Victor Turner's main themes. The author's interest in the subject emerges since his early works based in the fieldwork among the LundaNdembu in the 1950's. The paper examines Turner's approach to ritual in this initial phase of his career and takes the concept of ritual symbol as a guideline. This concept encapsulates the core aspects of Turner's view of ritual and is examined "in action", that means in its movement through different texts. The ritual symbol is seen as one locus of Turner's work in which his efforts of conceptualization are strongly

* Versões preliminares deste texto foram apresentadas no Laboratório de Análise Simbólica (PPGSA/ IFCS/UFRJ) em 2006, e na mesa-redonda “Entre o ato e o símbolo”, na Anpocs, 2009. Agradeço os comentários e sugestões então recebidos, em especial a Emerson Giumbelli, Vania Cardoso, Marco Antonio Gonçalves, Marnio Teixeira-Pinto, John Dawsey, Fernanda Peixoto, Marisa Peirano, Els Lagrou, José Reginaldo Gonçalves.

Horizontes Antropológicos, Porto Alegre, ano 18, n. 37, p. 103-131, jan./jun. 2012 
associated with his keen ethnographic sense of ritual. With this notion, Turner articulated cognitive and experiential dimensions of social life, and sought to unravel its unconscious dimensions. Turner's development of a semantic and hermeneutic approach to the ritual symbol emerges as a compromise between two quite different directions of his thought: his metaphysical and religious tendencies and his movements towards Freudian psychoanalytic formulations.

Keywords: ethnography, ritual, symbol, Victor Turner.

Man has to be continually extending the limits of the sayable by active contemplation of the unsayable. Silence is not the answer, silence is our problem.

Victor Turner (Revelation and divination)

A obra de Victor Turner (1920-1983) é tão vasta quanto multifacetada. ${ }^{1}$ Richard Schechner (1987, p. 7), ao comentar os últimos trabalhos do autor, já indicou sua "característica incompletude". Talvez por isso mesmo, essa obra permaneça provocando, hoje como ontem, leituras e releituras; e continue estimulando pesquisas e reflexões, na antropologia mundial e na antropologia feita no Brasil, onde o autor esteve, em 1978, pelas mãos de Roberto DaMatta, um interlocutor próximo e ele mesmo um renovador dos estudos de ritual no país. ${ }^{2}$

Entretanto, em que pese a inquietude e mesmo o ecletismo desse prolixo percurso, Turner foi sempre fiel a si mesmo. Seus textos caracterizam-se pela presença de um pathos que interpela muito diretamente o leitor e o convida a

\footnotetext{
1 As ideias de Turner se ramificaram em diversos campos. A bibliografia de estudiosos que acolheram e desenvolveram de modo próprio aspectos de suas ideias não para de crescer. Ver a respeito St. John (2008). A discussão dessa vasta bibliografia extrapola em muito os limites deste artigo.

2 Entre os anos 1970 e 1980, foi intenso o diálogo da antropologia brasileira com Victor Turner (DaMatta, 1973, 1979; Leopoldi, 1978; Maggie, 2001) e vice-versa (Turner, 1987). Esse diálogo foi retomado em DaMatta (2000, 2007). O uso das ideias do autor disseminou-se desde então. Ver, entre outros, Vogel, Mello e Barros (1998) e Cavalcanti (2006). Na atualidade, destacam-se contribuições na área dos estudos de performance. Rubens Alves da Silva (2005) examinou a noção de drama em Turner enfatizando suas conexões com o tema da liminaridade e da performance. Dawsey (2005) enfocou as conexões entre os temas do drama e da performance e da experiência. Nesse contexto, eu mesma (Cavalcanti, 2007) examinei a noção de drama social em Turner (1996). Até o momento, apenas três livros de Victor Turner foram traduzidos para o português: O processo ritual (Turner, 1974); Floresta de símbolos: aspectos do ritual ndembu (Turner, 2005) e Drama, campos e metáforas (Turner, 2008).
}

Horizontes Antropológicos, Porto Alegre, ano 18, n. 37, p. 103-131, jan./jun. 2012 
experimentar uma certa communitas com o autor, um lugar de despojamento e de compartilhamento de aspectos universais da experiência humana - o fluxo do tempo, a finitude, a doença, as aflições, a cura, o sofrimento, as contradições e tensões e, sempre, a empatia e as afeições.

Ao mesmo tempo, os variados aspectos de sua obra religam-se sempre, de algum modo, ao tema matriz do ritual, que funciona como uma espécie de elemento propulsor de seus rumos intelectuais e existenciais (Grimes, 1990). Ao ritual associou-se o interesse pela performance e pela experiência, articulado em seus últimos e/ou póstumos trabalhos (Turner, 1982, 1985, 1986, 1987), que alimentaram o diálogo interdisciplinar entre antropologia e as artes cênicas e narrativas configurando a área interdisciplinar dos estudos de performance. Também os ressonantes temas da communitas e da antiestrutura (Turner, 1974a; Turner; Turner, 1978) - uma contribuição central à antropologia das religiões (De Boeck; Devish, 1994; Deflem, 1991; Weber, 1995) - derivam da expansão da abordagem do ritual aos processos sociais como um todo. ${ }^{3}$ A própria conversão da família Turner ao catolicismo, no final dos anos 1950, liga-se à relevância do ritual em sua visão de mundo (Engelke, 2004, p. 26). ${ }^{4} \mathrm{O}$ tema do ritual, marcante já em seus primeiros trabalhos (Turner, 1953, 1996) ramificou-se e, mesmo, estilhaçou-se por toda a obra de Victor Turner.

O movimento de distanciamento do autor dos terrenos clássicos da antropologia tem sido muito valorizado no contexto da guinada antropológica pós-moderna (Engelke, 2004, p. 32). Entretanto, como busco argumentar, a fecundidade, os impasses e a heterodoxia de suas formulações na primeira fase de sua obra mantêm incontestável interesse para a renovação dos estudos de

3 Schechner editou o livro póstumo de Turner (1987), Anthropology of performance. Turner e sua esposa, Edith, escreveram juntos Image and pilgrimage in christian culture (Turner; Turner, 1978). Edith Turner (Engelke, 2004, 2008) foi, desde o primeiro momento, uma ativa colaboradora de Turner. Depois de sua morte em 1983, ela publicou diversos trabalhos explorando a seu próprio modo os temas abordados pelo marido. Exemplar nessa direção é, por exemplo, o trabalho de Alexander (1991), que elabora o conceito turneriano de antiestrutura ritual para análise dos experimentos teatrais de Jerzy Grotowski. O impacto da noção de communitas e de antiestrutura no campo das humanidades foi também grande, vale citar seu proveitoso uso por historiadores como Lonsdale (1993), Le Roy Ladurie (1979) entre outros.

4 Remeto a trecho de carta de Victor Turner ao amigo John Bare, onde o autor comenta como a família havia “percebido quão rica e satisfatória era a vida coletiva devocional” (Engelke, 2004, p. 26, tradução minha).

Horizontes Antropológicos, Porto Alegre, ano 18, n. 37, p. 103-131, jan./jun. 2012 
rituais e performances. Vale a pena, assim, revisitar a abordagem do ritual que emerge de modo bastante nítido nessa fase da obra de Turner, diretamente baseada na experiência de campo entre os ndembus vivida nos anos $1950 .{ }^{5}$ Além de valiosa em si mesma, a abordagem do ritual então empreendida guarda laços orgânicos com o que se seguiu, e permite elucidar aspectos relevantes, ontem como hoje, dos problemas envolvidos no esforço de apreensão da natureza simbólica da experiência humana (Sahlins, 1976). Nela destaca-se, em especial, a elaboração do conceito de símbolo ritual (Turner, 2005) que será o fio condutor destas reflexões.

\section{Floresta de livros}

O primeiro trabalho de Victor de Turner sobre os lunda-ndembus, a monografia Lunda rites and ceremonies (Turner, 1953) [doravante LRC], dedicou-se ao exame de seus ritos e símbolos. ${ }^{6}$ Já em Schism and continuity, de 1957 (Turner, 1996) [doravante SC], como veremos com mais vagar, o ritual não só ocupou lugar central na restauração e constituição dos laços sociais ndembus, como Turner reiterou diversas vezes a promessa de um próximo livro integralmente dedicado ao assunto: "Uma sequência deste livro, que terá o ritual ndembu como tópico central, está em preparação." (Turner, 1996, p. 331, tradução minha); ou ainda, antes da discussão do ritual chihamba, que ocuparia lugar notório em sua obra subsequente: "Eu espero realizar um exame detalhado da estrutura cultural do ritual ndembu em um estudo separado." (Turner, 1996, p. 303, tradução minha).

Turner, entretanto, não cumpriu exatamente a promessa de escrever um livro especificamente sobre o simbolismo e os rituais ndembus: os artigos e

\footnotetext{
5 Os lunda-ndembus, geralmente designados por Turner simplesmente como ndembus (Turner, 1996, p. 1) habitavam a porção ocidental do distrito Mwinilunga na região noroeste da antiga Rodésia do Norte, atual Zâmbia. Turner nos diz ter optado pela pesquisa no quadrante mais ao norte e mais tradicional da região habitada pelos ndembus. A pesquisa de campo foi realizada em dois períodos: entre dezembro de 1950 e fevereiro de 1952, e entre maio de 1953 e junho de 1954.

6 Manning (1990) traz uma detalhada relação das publicações de Victor Turner, que vão de 1952 a 1986.
} 
ensaios escritos entre 1957/58 e 1964, em resposta à reiterada promessa feita em SC, foram reunidos em três livros. ${ }^{7}$ São eles:

1) Floresta de símbolos, de 1967 (Turner, 2005) [doravante FS], que acolhe artigos escritos ao longo de todo esse período;

2) The drums of affliction (Turner, 1968) [doravante DA], que examina os rituais de aflição ndembu, trazendo a detalhada descrição etnográfica de dois deles, o nkula e o ihamba, bem como do rito de iniciação feminina nkang'a;

3) Revelation and divination (Turner, 1975) [doravante RD], que incorpora trabalhos elaborados entre 1958 e 1962. Os dois principais capítulos da primeira parte dedicam-se à análise de chihamba, visto por Turner como o principal rito de aflição ndembu, e o terceiro capítulo explora as conexões entre o simbolismo da brancura, que emerge nesse rito, com simbolismos da brancura na literatura e religiões ocidentais. A segunda parte do livro analisa o simbolismo divinatório ndembu.

Esses trabalhos, iniciados no contexto da interlocução de Victor Turner com outros autores marcantes da antropologia social inglesa, marcam seu deslocamento dos marcos conceituais do estrutural-funcionalismo rumo à análise simbólica propriamente dita e à abordagem processualista. Expressam a singularidade de seu pensamento que logo encontraria, de 1964 em diante, acolhimento no ambiente norte-americano, então permeado pela contracultura (Engelke, 2004).

Em especial, os três livros acima indicados são, a meu ver, aqueles responsáveis por avaliações sobre o autor que assinalam a riqueza de suas análises simbólicas, como aquela de G. Lenclud (1991, p. 221, tradução minha), para quem: "Para além da riqueza excepcional dos materiais etnográficos

\footnotetext{
A maior parte desses trabalhos foi elaborada enquanto Turner esteve vinculado à Universidade de Manchester, na Inglaterra, a partir de 1955. Durante esse período, a estadia no Centro de Estudos Avançados em Ciências Comportamentais da Universidade da Califórnia, entre 1961-1962, serviu como porta de entrada no mundo acadêmico norte-americano, onde ele assumiu, em fevereiro de 1964, posto na Universidade de Cornell. Na Universidade de Chicago, para onde Turner iria em 1968, ele trabalhou com uma dupla vinculação, ligando-se tanto ao departamento de antropologia como ao Comitê de Pensamento Social, instância multidisciplinar que lhe teria permitido mais liberdade intelectual (Engelke, 2004, p. 29, 32). Em 1977, ele foi para a Universidade de Virginia, onde até sua morte, em 1983, foi professor de antropologia e religião. Para mais detalhes da biografia de Turner, ver Babcock, (1984).
}

Horizontes Antropológicos, Porto Alegre, ano 18, n. 37, p. 103-131, jan./jun. 2012 
apresentados à análise, a originalidade da contribuição de Turner para o conhecimento do fenômeno ritual e da atividade simbólica deve-se ao fato de sua obra conjugar pontos de vista geralmente mantidos separados na antropologia." Ou como a de Peirano (1993), para quem Turner inovou ao tornar as ideias de sistema social e de sistema de crenças e práticas coextensivas.

Aos poucos, emerge desses livros, muito organicamente, uma nova etapa da obra de Turner. "Chihamba, the white spirit", publicado originalmente em 1962, que veio a compor RD (Turner, 1975), é certamente o tema no qual se opera uma decisiva transição de abordagens (Engelke, 2004). ${ }^{8}$ Entretanto, a meu ver, é O processo ritual, de 1969 (Turner, 1974b) [doravante PR] que, ao desenvolver o conceito de communitas a partir da noção clássica de liminaridade proposta em 1909 por Van Gennep (1960), inaugura efetivamente uma nova etapa da carreira de Turner. ${ }^{9} \mathrm{~A}$ amplitude do espectro de tópicos relacionados por Victor Turner ao ritual mencionada por Grimes (1990, p. 145) - que abrange das peregrinações e movimentos religiosos milenaristas às comunidades hippies, expressões literárias e políticas, drama e experiências teatrais até a fisiologia cerebral - desenhou-se a partir de então.

Como coletâneas de artigos em sua maior parte republicados, os três livros mencionados acima - FS, DA e RD - aqueles que reúnem os artigos escritos na sequência de SC - estão repletos de referências intercruzadas e fazem parte, sem sombra de dúvida, do mesmo impulso intelectual. Porém, isso significa também que o material analítico e descritivo sobre os rituais ndembus espraiou-se, de modo fragmentário e muitas vezes repetitivo, por entre eles. Por essa razão, mesmo nesse ambiente mais restrito, escolhas se fizeram necessárias e orientaram o caminho das reflexões deste texto.

Nesse período, a formulação conceitual que condensa o interesse de Turner pelos rituais e símbolos é a noção de símbolo ritual, aprofundada no

8 Essa abordagem representaria mesmo, como indicaram Babcock e MacAloon (1988, p. 7 apud Engelke, 2004, p. 27, tradução minha), "a quebra com a tradição antropológica na qual ele havia sido treinado". Ou como formula o próprio Engelke (2004, p. 28, tradução minha): “Como uma resposta à abordagem 'sociológica' das mesmas questões em Cisma e continuidade, 'Chihamba' deve de fato ser visto como um movimento radical. Ele reúne as preocupações do casal Turner com literatura, religião e a antropologia do 'mundo real' de um novo modo ao fundir conscientemente o mundo de suas vidas cotidianas com o mundo de suas ideias antropológicas. De fato, ‘Chihamba' foi a peça mais radical publicada por Turner em vida."

9 Esse livro reúne as Conferências Lewis Henry Morgan proferidas por Victor Turner na primavera de 1966 na Universidade de Rochester (Engelke, 2004, p. 30). 
famoso artigo "Símbolos no ritual ndembu”, que, escrito em 1958, veio a compor o primeiro capítulo de Floresta de símbolos (Turner, 2005). ${ }^{10}$ Ronald Grimes (1990, p. 145) indicou, com pertinência, não só os insights como as inconsistências, e mesmo contradições, existentes entre as definições turnerianas de ritual, suas teorias de ritual e sua apreensão teórico-experiencial dos sentidos do ritual. Comentou (Grimes, 1990, p. 141) a surpreendente pobreza da definição de ritual que, nunca revista por Turner, abre este artigo: "Por ' ritual', entendo o comportamento formal prescrito para ocasiões não devotadas à rotina tecnológica, tendo como referência a crença em seres ou poderes místicos.” (Turner, 2005, p. 49). ${ }^{11}$ Indicou também a natureza assistemática de suas teorias de ritual. Em especial, a ideia mesma do símbolo ritual como unidade mínima do comportamento ritual (Turner, 2005, p. 49) deixa de fora muito de ordinário e mesmo de extraordinário do que ocorre nos rituais concretos. ${ }^{12}$ Grimes (1990, p. 145) assinala, entretanto, que a riqueza do trabalho de Victor Turner repousa, sobretudo, em sua apreensão teórico-existencial do ritual, em seu "sense of ritual".

Seguindo essas sugestões, proponho que nos afastemos das dimensões sabidamente problemáticas de suas definições e examinemos, bem à maneira de Turner, o conceito de símbolo ritual em ação por entre diferentes textos. A densidade do percurso de pesquisa que levou à formulação dessa noção e, num segundo momento, seu uso analítico favoreceram imensamente a dimensão etnográfica da obra turneriana. Etnografia, teorização e o aguçado sentido do ritual de Victor Turner associaram-se aqui de modo notável. Com o símbolo ritual, Turner rearticula sob nova luz (e novas sombras) a fecunda questão da

${ }^{10}$ Em seu verbete sobre a obra de Turner, Lenclud (1991) considera o capítulo IV, “Betwix, between”, o capítulo central de FS, pela retomada do conceito de rito de passagem. Entretanto, ressalto aqui, junto com Oring (1993), o interesse central do capítulo I, em função da teoria do símbolo que elabora. Observo que Oring (1993) referencia sua cuidadosa discussão da presença freudiana na teoria do símbolo ritual em Turner (1973), um artigo que retoma basicamente os pontos já elaborados anteriormente (Turner, 2005).

${ }^{11}$ Grimes (1990, p. 141) chamou atenção, entre outros problemas dessa definição, para a suposição da prioridade da crença sobre o ritual e para a desconsideração das instâncias de disjunção e dissonância entre ritual e crença. Observa também como o próprio Turner estava longe de operar dentro dos estreitos e problemáticos limites teóricos dessa definição.

${ }^{12}$ Vale ainda indicar a oposição entre ritual e cerimônia, aquele associado aos processos de transição e transformação e esta a ações confirmatórias; há ainda a flutuação da ideia do dramático como uma qualidade funcional do ritual ligada às situações de conflito social (Grimes, 1990, p. 142-144).

Horizontes Antropológicos, Porto Alegre, ano 18, n. 37, p. 103-131, jan./jun. 2012 
relação entre conceituação e experiência posta para a antropologia desde 1912 por Durkheim (1996).

Por essa razão, a noção de símbolo ritual elaborada em 1958 (Turner, 2005) é o pivô em torno do qual se articulam as indagações e reflexões deste texto que se movimenta para trás, considerando LRC (Turner, 1953), SC (Turner, 1996), e para frente, considerando RD (Turner, 1975). ${ }^{13}$

\section{0 ritual entre os ndembus}

Em que pese a fecundidade de muitos insights e a síntese conceitual operada com o símbolo ritual, Turner nunca articulou o conjunto dos rituais ndembus em um sistema integrado. ${ }^{14}$ Apenas em seu primeiro trabalho sobre os lunda-ndembus, RLC (Turner, 1953), encontramos uma útil e detalhada descrição de conjunto das diferentes modalidades rituais que se espalhariam posteriormente por sua obra. Haveria, nos diz ele, dois tipos principais de ritual:

1) os rituais de aflição, relacionados à associação do infortúnio e da doença com a ação de espíritos dos mortos. Dentre as principais formas da aflição, já se destaca chihamba, ritual que abarca tanto homens como mulheres tratando da doença de modo geral ou das desordens reprodutivas. Os lundas diziam que chihamba era um ritual tão importante quanto mukanda, o rito de iniciação masculina, e que muita gente vinha participar dele (Turner, 1953, p. 386).

${ }^{13}$ O exercício analítico proposto poderia se ampliar, revisitando e considerando o conjunto mais amplo das etnografias de rituais apresentados em FS, DA e RD - como mukanda, nkang'a, ilhamba para mencionar apenas alguns deles. Turner elenca, por exemplo, entre uma das razões para o exame do rito de aflição nkula, o fato de ele prover documentação mais completa para as hipóteses elaboradas em "Símbolos no ritual ndembu” (Turner, 1968, p. 54). Dentro dos limites deste artigo importa assinalar os laços orgânicos existentes dentro de todo o conjunto.

${ }^{14}$ Oring (1993, p. 290) comentou como a dimensão comparativa da análise simbólica aspirada por Turner foi explorada apenas ocasionalmente em sua obra. A comparação, quando empreendida, prestar-se-ia, sobretudo, a indicar a presença das mesmas propriedades simbólicas nos casos considerados (por exemplo Turner, 1975). Creio que o exame comparativo "intracultural” mais acabado é aquele das cores no ritual ndembu empreendido no capítulo III de FS.

Horizontes Antropológicos, Porto Alegre, ano 18, n. 37, p. 103-131, jan./jun. 2012 
2) os ritos de crise de vida que consistiriam em: a) mukanda, ${ }^{15}$ a iniciação masculina; b) nkang'a, a iniciação feminina; c) os funerais.

Nessa primeira monografia, Turner recorre apenas descritivamente à noção de ritos de passagem de Van Gennep (1960), como faziam nos anos 1950 diversos pesquisadores, entre eles Audrey Richards (1982) em sua notável abordagem da cerimônia de iniciação feminina, chisungu, entre os bembas, também da atual Zâmbia. ${ }^{16}$

Entre essa monografia de 1953 e os três livros acima mencionados (Turner, 1968, 1975, 2005), dedicados à vida simbólica dos ndembus, encontra-se o livro de estreia do autor no cenário antropológico mais amplo, Schism and continuity in an African society (Turner, 1996), publicado em 1957. O livro corresponde à sua tese de doutoramento orientada por Max Gluckman e desenvolvida sob a égide do Rhodes Livingstone Institute entre 1950 e 1954. Foi saudado na época por Gluckman (1990 $)^{17}$ pela valorização do dinamismo do estudo dos "casos em processos". O operador conceitual dessa abordagem dinâmica tão valorizada por Gluckman era, como sabemos, o conceito de drama social.

Esse conceito, até hoje fecundo, atrairia mais tarde o interesse antropológico por outras razões: Clifford Geertz (1997) indicou o uso denso e consistente da metáfora do drama, oriunda das artes cênicas, para a elucidação da dimensão processual da vida social por Turner. Essa noção permitiu integrar, desde sua formulação, a experiência subjetiva à dinâmica da ação social, e relativizou desse modo as determinações das posições socioestruturais para a compreensão do sentido da conduta dos atores. A noção de drama social,

${ }^{15}$ Mukanda é o rito de circuncisão masculina analisado em Turner (1962). Sua análise é retomada e ampliada no capítulo VII de FS (Turner, 2005).

${ }^{16}$ Apenas com o livro Essays on the ritual of social relations, organizado por Max Gluckman (1962), e com o belo artigo de Victor Turner "Betwix, between: o período liminar nos 'ritos de passagem'” - que, publicado inicialmente em 1964, viria a constituir o capítulo IV de FS (Turner, 2005) - o potencial heurístico e conceitual da noção de ritos de passagem viria à luz.

17 Como sabido, no começo de sua carreira, Turner integrava o chamado grupo de Manchester e dos pesquisadores do Rhodes Livingstone Institute liderados por Max Gluckman (Engelke, 2004; Schumaker, 2004). A proximidade intelectual existente entre eles pode ser percebida pela forte presença dos temas do conflito, da natureza processual da vida social e do papel integrador do ritual na obra de Gluckman $(1963,1974)$. Ainda nesse contexto, vale observar a centralidade da metáfora do teatro na análise de Hilda Kuper (1944) do ritual da realeza swazi, que fornece o material básico para a elaboração do conceito de ritos de rebelião de Gluckman (1974).

Horizontes Antropológicos, Porto Alegre, ano 18, n. 37, p. 103-131, jan./jun. 2012 
articulada em torno da noção de conflito e com suas fases sequenciais, fornecia uma moldura a um só tempo analítica e descritiva da dinâmica do sistema de relações sociais ndembus. Trazia também a percepção do fluxo temporal como uma dimensão fundamental da experiência social que acompanharia toda a obra de Turner (Cavalcanti, 2007).

Porém, já em SC, inicia-se também o decidido movimento teórico de Turner rumo à afirmação da centralidade do ritual e da vida simbólica na organização da experiência não apenas social como integralmente humana. ${ }^{18}$ Nele, o interesse pela concretude e materialidade dos rituais, já nítido em LRC (Turner, 1953), ganhou nova densidade analítica e etnográfica. Nesse novo contexto, os rituais ndembus emergirão como um mecanismo decisivo da ação social que pontua e atravessa as diferentes fases do drama - crise; ampliação da crise; regeneração; ruptura ou rearrumação. No entanto, é especialmente na terceira fase, aquela de regeneração, que o ritual ganha primazia. Encontra-se já aqui, em germe, o ponto sempre assinalado como uma das grandes contribuições de Turner às teorias do ritual, a apreensão de sua dimensão transformadora da experiência.

Isso emerge especialmente no capítulo $\mathrm{X}$, “A função politicamente integrativa do ritual” (Turner, 1996, p. 288-317), que guarda relação direta com o drama V, o último dos dramas sociais analisado no capítulo V, intitulado "Sandombu injuria e é injuriado (minhas próprias observações)" (Turner, 1996, p. 157-168). ${ }^{19}$ Não é meu propósito voltar às minúcias dessa análise, nem a suas consequências socioestruturais. Porém, para a compreensão do ritual chihamba e de seu simbolismo, vale resumir brevemente o drama V, que guarda laços orgânicos com ele.

Como sabemos, em SC, com o estudo dos episódios alinhados nos cinco dramas sociais analisados, Turner desvendou a forte tensão existente entre as duas principais linhagens - Nyachitang’a e Malabu - cuja aliança selava a unidade da aldeia Mukanza, permanentemente ameaçada pela sombra da

18 Esse ponto é assinalado também por Engelke (2004, p. 25).

19 Essa conexão é feita pelo próprio Turner: "Eu indiquei muitas conexões entre as ações e veículos simbólicos em chihamba e aspectos da estrutura e da dinâmica social ndembu. Também devotei todo um capítulo de meu livro, Cisma e continuidade, o capítulo $\mathrm{X}$, a um estudo detalhado dos principais efeitos sociais de uma performance específica do chihamba na aldeia Mukanza e no seu campo de relacionamentos interaldeias.” (Turner, 1975, p. 19, tradução minha). 
cisão. ${ }^{20}$ Essa aliança consumara-se, por assim dizer, no casamento mesmo do chefe da aldeia Mukanza Kabinda (Nyachitang'a) com Nyamukola (Malabu). No quinto drama examinado, a sequência de ações se inicia com o conflito de Sambombu, ${ }^{21}$ um dos membros da linhagem Nyachitang'a, com sua segunda esposa, que vinha a ser filha do chefe da aldeia, Mukanza Kabinda. No calor dos desentendimentos, Sandombu teria acusado sua sogra, Nyamukola (da linhagem Malabu) de ter passado um feitiço à sua filha para que esta, por sua vez, o enfeitiçasse. Enquanto tudo isso acontecia, entretanto, num episódio de conflito entre a aldeia Mukanza e uma aldeia vizinha, o mesmo Sandombu defendeu ágil e publicamente a sua própria aldeia. Outro adulto de Mukanza, membro da linhagem Malabu, a mesma de Nyamukola, defende então Samdombu, que se retrata publicamente e paga à sua sogra apenas uma multa. A crise desembocará, assim, não no aprofundamento da tensão e na eventual na fratura da unidade da aldeia, mas em regeneração. Ora, essa regeneração é promovida justamente pela realização do ritual que constitui um dos focos do capítulo X, chihamba, um ritual de cura, situado dentro do "plástico e adaptável sistema ritual dos ndembus”.

Turner nos alerta, cauteloso, que empreenderia simplesmente o isolamento dos aspectos sociológicos do complexo ritual e, quase se desculpando, afirma que "o relato de suas principais características culturais é necessário, se queremos apreender claramente suas implicações sociológicas" (Turner, 1996, p 303, tradução minha). Suas reflexões, entretanto, ampliam e mesmo deslocam a visão do autor sobre a natureza do vínculo social. ${ }^{22}$ Turner dialoga e contrapõe-se aqui, todo o tempo, a Meyer Fortes e Evans Pritchard, ${ }^{23}$ ao argumentar que a unidade dos ndembus não é política, mas

${ }^{20}$ Mukanza, ficamos sabemos com Engelke (2004, p. 26), é o nome fictício da aldeia Kajima, tema do primeiro artigo autoral de Edith Turner que, escrito em 1954, só viria a ser publicado em 1987 sob o título The spirit and the drum (Turner, E., 1987).

${ }^{21}$ De todos os atores/sujeitos sociais que emergem de modo tão vívido em SC, Sandombu é o personagem predileto de Max Gluckman (1996, p. XIX).

${ }_{22}$ Turner manteria, entretanto, em toda sua obra a distinção entre cultural e social, e mesmo aquela entre sociedades industriais e sociedades tradicionais. Esta última, por exemplo, é central na distinção liminar versus liminoide (Turner, 1982).

${ }^{23}$ Os textos de referência são Fortes (1945, 1949), Evans-Pritchard (1948) e Fortes e Evans-Pritchard (1940). Vale observar como também esses autores, cada qual à sua maneira, ampliariam nas fases subsequentes de suas carreiras o interesse pela dimensão simbólica da vida social. Ver em especial Fortes (1987) e Evans Pritchard (1956).

Horizontes Antropológicos, Porto Alegre, ano 18, n. 37, p. 103-131, jan./jun. 2012 
moral (Turner, 1996, p. 289). Pois, o sentido de pertencimento a um povo ou "sociedade" ndembu se forja nos cultos rituais, sejam eles de passagem ou de cura. Nesses ritos, os símbolos evidenciados não enfatizariam nem a matrilinearidade, isto é, o princípio sociológico básico da descendência em comum, a fundar a dinâmica da unidade territorial das aldeias ndembus, nem a ocupação comum de localidades particulares. Enfatizariam sempre, nos diz Turner, os interesses que todos os ndembus teriam em comum para além dessas clivagens estritamente sociológicas: neles, "a aflição de cada um é preocupação de todos” (Turner, 1996, p. 302, tradução minha).

Também, os símbolos dominantes no agregado de objetos e atividades simbólicos associados a cada ritual não refletem ou expressam os principais aspectos da estrutura social, mas antes os valores que todos os ndembus possuem em comum [...]. A unidade primordial dos ndembus se expressa na composição das assembleias rituais. (Turner, 1996, p. 290, grifo do autor, tradução minha). ${ }^{24}$

Trata-se de uma "comunidade de sofrimento", como assinalaria em 1957 Max Gluckman (1996, p. XIX).

O princípio dos ritos de cura, ou ritos de aflição, é a transformação da perturbação em poder curativo: "o adepto aplaca o espírito ofendido" em um processo que trata de "trazer o ancestral ofendido de volta à memória" (Turner, 1996, p. 298, tradução minha). Turner assistiu a 31 performances de 15 tipos de ritos de aflição, e detalhará o ritual chihamba assistido em seu segundo período de permanência. ${ }^{25}$ Chihamba era considerado "um ritual muito pesado"; "um espírito que se manifesta no chihamba pode matar a pessoa afligida”; "uma manifestação específica do espírito ancestral” (Turner, 1996, p. 303, tradução minha); “uma espécie de compêndio de todos os infortúnios que podem acontecer a alguém” (Turner, 1996, p. 304, tradução minha). Turner indica que os 71 adeptos/candidatos participantes eram de 20 aldeias

\footnotetext{
${ }^{24}$ A dimensão etnográfica da análise sociológica de Turner é fascinante ao demonstrar minuciosamente como a interconexão entre adeptos de diferentes aldeias e de diferentes grupos de parentesco em um culto desempenha, afinal, uma função política integrativa (Turner, Turner, 1996, p. 296). A hesitação do autor entre o cultural e o social é grande nesse momento. Muitas vezes (Turner, 1996, p. 303), entretanto, o ritual é reduzido à função social compensatória de integração social em grupo humano que não disporia de muitas outras formas de garanti-la.

25 Turner (1975. p. 41) nos diria mais tarde que Muchona desempenhava, junto com outros curadores, um papel importante nesse ritual. Sobre Muchona, ver em especial o capítulo VI, de FS (Turner, 2005).
}

Horizontes Antropológicos, Porto Alegre, ano 18, n. 37, p. 103-131, jan./jun. 2012 
diferentes, pertencentes, por sua vez, a sete regiões diferentes. Registra também o grande número de espectadores nas fases públicas do ritual, que teria chegado a 400 pessoas em uma das noites (Turner, 1996, p. 312-313).

Nesse culto emerge o personagem/artefato Kavula, que não é, entretanto, o espírito ancestral (a ser nomeado e rememorado) que aflige o paciente/candidato a adepto, mas um espírito que tem existência independente. Segundo a exegese ndembu, Kavula seria um estranho ser sobrenatural, nomeado por um termo antigo para o relâmpago, ligado também ao termo para a chuva, a mandioca e outros grãos cultivados. No rito, a morte de Kavula remove finalmente a doença, e instaura a saúde e a fertilidade (Turner, 1996, p. 304).

Com chihamba, e com Kavula, emergem, já em 1957 com SC (Turner, 1996), os principais eixos da teoria do símbolo ritual explanada por Turner no artigo de 1958 (Turner, 2005): sua dinâmica e eficácia, sua multivocalidade, e a diferenciação entre a expressão manifesta e o conteúdo latente, associada à apreensão da ambivalência afetiva. Emerge também o tema da revelação, elaborado em RD (Turner, 1975), no texto escrito em 1962, ao qual se liga a dimensão de intensidade da experiência subjetiva (a um só tempo cognitiva e emocional) propiciada no contexto ritual a partir do que se desdobrariam tanto o interesse metafísico e religioso de Turner quanto seu grande interesse pela performance.

\section{Kavula, o símbolo em ação}

Na terceira fase do chihamba, a fase ku-tumbuka (de reagregação), na noite do primeiro dia, Kavula - um adepto sênior disfarçado - atua como um palhaço. Com voz gutural ele escarnece e fala indecências para os candidatos/ pacientes na casa do principal paciente/parente do culto em questão. A principal paciente era, no caso analisado, Nyamukola, sogra de Sambombu e esposa do chefe Mukanza Kabinda, foco das tensões indicadas no drama V (Turner 1996, p. 309). Nessa ocasião, Kavula faz estranhas perguntas a todos os candidatos/pacientes e atribui a cada um nomes rituais característicos e exclusivos (Turner, 1996, p. 304). No dia seguinte, se faz uma armação móvel em um lugar secreto (sagrado, isoli) na mata próxima da aldeia. Essa armação, uma espécie de boneco, será agora Kavula. ${ }^{26}$ Uma corda é amarrada a esse artefato

${ }^{26}$ Kavula é masculino e o espírito que aflige é sempre feminino. Toda a teatralização do Kavula é atribuição masculina (Turner, 1996, p. 307). 
e um adepto sênior o manipula, fazendo-o dançar. Todos se ajoelham e rastejam diante da imagem branca de Kavula (isto é, tornada branca, por um lençol ou uma pele animal embranquecida pela mandioca). Kavula é, nesse momento, "aquele que tudo sabe e que devemos louvar": "Um por um eles rastejam em direção à cobertura de folhas que circunda a imagem branca de Kavula, batendo a cabeça no chão conforme avançam, primeiro para um lado e depois para o outro. As mulheres espremem seus seios para aleitar o chefe enquanto avançam. Kavula, nesse momento, é comparado a Mwantiyanvwa [o ancestral originário]” (Turner, 1996, p. 304, tradução minha). Ao alcançar o ancestral/ artefato, cada paciente/candidato é, então, instruído a matar Kavula, batendo em sua cabeça com um chocalho (um chocalho de forma especial e especialmente esculpido para o adepto/paciente). Os candidatos são, em seguida, levados embora pelos adeptos seniores. Quando voltam, não mais encontram o lençol branco, e o pequeno altar está cheio do sangue de uma galinha sacrificada. Os adeptos seniores dizem aos candidatos que eles mataram Kavula. Ao longo de todo esse dia, os candidatos/pacientes foram chamados de, e tratados como, “escravos de Kavula”, vestindo-se de andrajos. Kavula, nos diz então Turner, é um símbolo ambivalente, que preside sobre a fertilidade, simboliza a um só tempo a autoridade benevolente (o avô que faz brincadeiras jocosas com os netos, e pode retirar a doença e o infortúnio), e o lado mais opressivo da autoridade ancestral em uma sociedade cheia de conflitos de parentesco e com senhores e escravos (Turner, 1996, p. 305).

Em SC, isso tudo introduz a análise sociológica de uma performance específica, referente ao Drama Social V já mencionado. Turner (1996, p. 316, tradução minha) reafirma: "Eu espero estabelecer em um livro subsequente como, no curso de um ritual, símbolos e comportamento verbal são manipulados de modo a descarregar tensões nos sistemas sociais e a reintegrar os membros da assembleia ritual aos abalados grupos sociais ao qual pertencem.” Dentro dos limites assumidos, ele chama atenção para a consistência da estrutura cultural com as suas funções sociais.

O exame do simbolismo do chihamba retornará, entretanto, na obra de Turner para exame detido nos dois primeiros capítulos de RD (Turner, 1975) "Chihamba, the White Spirit" e "Some notes on the symbolism of Chihamba" (publicados respectivamente em 1962 e 1961), e servirá de base para o experimento de comparação transcultural no terceiro capítulo, onde a brancura de Kavula será comparada a outros símbolos de brancura na literatura e religiões 
ocidentais em especial, o Canto XXI do Paraíso de Dante Alighieri, a imagem de Jesus Cristo como o cordeiro de Deus, e Moby Dick, a poderosa baleia branca de Herman Melville. Nesse novo momento intelectual, como esclarece Turner (1975, p. 16) na introdução, chihamba associa-se ao sentido de totalidade dos ndembus, entendido agora não mais em sua dimensão sociológica, mas como expressão da retomada da sua conexão direta dos sujeitos com a unidade do fluxo da experiência.

Essas abordagens do chihamba indicam questões relevantes na teoria turneriana do símbolo ritual.

\section{Problemas do símbolo ritual}

James Clifford (1998), que renovou o estudo das etnografias clássicas, ao propor o exame dos diferentes registros internos à sua construção narrativa, ${ }^{27}$ deteve-se nas obras de Turner. Embora Clifford assinale a inexistência, em sentido estrito, de vozes de diferentes ndembus nas obras de Turner (entendendo-se por vozes as expressões plenas de pontos de vista diversos sobre a experiência), ${ }^{28}$ ele indica, com propriedade, a variação entre citações diretas e evocações anônimas na estrutura discursiva dos trabalhos do autor, vistas como exemplos reveladores pela interação entre a exposição monofônica e a polifônica. Considera-as mesmo "retratos soberbamente complexos de símbolos rituais e crenças Ndembu”; textos que “[...] ao darem um lugar visível às interpretações nativas dos costumes, expõem concretamente os temas do dialogismo textual e da polifonia” (Clifford, 1998, p. 51-53).

Há duas observações pertinentes à natureza polifônica da narrativa etnográfica de Victor Turner realçada por Clifford (1998). Compreendemo-la melhor, creio, se a relacionamos, de um lado, à acuidade descritiva que permeia muitas das monografias da época e vigorava desde os anos 1920 com as exigências postas por Malinowski (1976); de outro, à teoria propriamente dita do

\footnotetext{
${ }^{27}$ A ideia turneriana de que as performances sociais encenam histórias poderosas (tanto míticas quanto do senso comum), que proporcionariam ao processo social uma retórica, uma forma de enredo e um significado foi também usada por Clifford (1998, p. 63) para renovar a leitura antropológica das etnografias clássicas, vistas elas mesmas como “alegóricas”, isto é, performances com um enredo estruturado através de histórias poderosas. Sobre Clifford, ver Gonçalves (1998).

${ }^{28}$ Vale notar, entretanto, que os relatos dos dramas sociais de SC trazem, de modo empático, diferentes vozes ndembus.
} 
símbolo ritual elaborada por Turner. Pois, para Turner (2005), o símbolo é, ele mesmo, polifônico e multivocal.

Todos aprendemos, no capítulo I de FS, os níveis de exegese tão importantes na metodologia da análise simbólica proposta por Turner (Turner, 2005, p. 50-56), que abarcam: 1) a descrição da forma externa e concreta do símbolo, de sua materialidade; 2) a exegese nativa; 3) os contextos de uso observados pelo antropólogo, onde se situam a dimensão operacional - a maneira como se usa o símbolo no curso da ação; e aquela posicional - a relação de um símbolo com outros símbolos rituais. Logo lembramos o esclarecedor exemplo fornecido pelo exame do símbolo ritual mudyi - a árvore leiteira, especialmente relevante no rito de iniciação feminina, nkang'a: 1) ao primeiro nível analítico corresponde o látex branco que a associa ao leite materno; 2) na exegese nativa, ela é a "nossa bandeira", significando que seu referente são todos os ndembus indistintamente; 3) no nível operacional, revela-se a discrepância entre a ação observada e a exegese nativa, pois esta enfatiza a união e daquela emergem clivagens e diferenciações; no nível posicional, trata-se de um símbolo dominante, foco primordial da interação, no qual se abrigam valores axiomáticos para o grupo estudado. A interpretação antropológica considerará todos esses níveis analíticos. O primoroso manejo dessa metodologia trouxe incontestável riqueza às análises de Turner, ao associar-se a uma maneira muito detalhada de apresentar e trabalhar os dados relativos ao manuseio de símbolos em contextos rituais.

O interesse pela ação dos símbolos e seu detalhado exame etnográfico, entretanto, segue de perto a orientação de trabalhos anteriores como o de Audrey Richards (1982) e de Monica Wilson (1954, 1957), a quem Turner dedicou, por sinal, o livro Floresta de símbolos (Turner, 2005). Richards examinou de modo notável as pequenas figuras de cerâmica apresentadas às meninas bembas púberes na fase liminar do chisungu. Esses objetos seriam fulcros da produção de canções e mitos denominados por um termo bemba traduzido como "coisas transmitidas” (Richards, 1982, p. 187, tradução minha). Uma dessas figuras - a estatueta de uma mãe grávida, que carrega quatro bebês ao mesmo tempo, um que mama no peito e três nas costas fará por sinal uma aparição importante, como símbolo ritual liminar no capítulo IV de FS (Turner, 2005, p. 149). Já em Audrey Richards, o método de exposição e de abordagem dos símbolos compõe uma narrativa heteróclita, organizada por diferentes níveis de interpretação, que vão do participante 
ordinário, ao especialistaritual, ao observador.ComoobservouLaFontaine(1972, p. XIII-XVI), Richards (1982) já estava atenta às tensões e conflitos inconscientes produzidos por traços característicos das estruturas sociais, ${ }^{29}$ à presença do "elemento emocional” no comportamento ritual, e já opera com a ideia da polivalência dos símbolos vistos como portadores de um amplo leque de referentes. Há em Turner a mesma atenção dada à observação da sequência concreta das ações, à exegese nativa seguida por comentários do antropólogo e, muito especialmente, à forma e à materialidade dos objetos manipulados. A proximidade de Victor Turner dessa tradição etnográfico-descritiva revelase nas frequentes enxurradas narrativas acerca da materialidade dos símbolos e de seus usos, e de transcrições diretas das exegeses nativas que permeiam seus artigos. ${ }^{30}$ Sob esse ângulo, a valorização da exposição narrativa polifônica valorizada por Clifford (1998) nos leva ao passado disciplinar.

Sob outro ângulo, a construção polifônica da narrativa de Turner deve-se à sua originalidade teórica, à densa elaboração do conceito de símbolo ritual em uma direção hermenêutica e à formulação de um método interpretativo geral (Manning, 1990). Essa teoria do símbolo foi sintetizada no artigo de 1958 "Símbolos no ritual ndembu" (Turner, 2005) que retomo brevemente.

Símbolos, para o autor, serão sempre objetos concretos que, situados entre outros símbolos, funcionam plenamente no contexto ritual. O ritual é, a um só tempo, um contexto sociocultural e situacional característico. Nesse ambiente, impregnado de crenças e valores, os símbolos exercem sua eficácia plena como articuladores de percepções e de classificações, tornando-se fatores capazes de impelir e organizar a ação e a experiência humanas e de revelar os temas culturais subjacentes. De um ponto de vista externo, Turner (2005, p. 50) nos dirá que: "Num ritual Ndembu, cada símbolo torna visível e acessível para a ação pública certos elementos da cultura e da sociedade Ndembu.” E já sabemos que o imbricamento dos símbolos na ação coletiva associa-se ao forte interesse de Turner pelo fluxo temporal das performances e pela natureza dramática da ação social. Porém, com a ideia de símbolo, Turner busca também, no cerne da experiência ritual, o laço que liga o sujeito à sua

29 Vale lembrar neste ponto que, em SC (Turner, 1996), a tensão inconsciente entre os princípios da matrilinearidade que governa a transmissão da herança e da virilocalidade que governa a regra residencial é uma das bases para a forma dramática do conflito assumida pelos processos sociais

30 Ver, por exemplo, o exame do ritual mukanda (Turner, 1962, 2005). 
própria experiência que, vivida coletivamente, é sempre também experimentada subjetivamente.

Nesse ponto crítico, emerge a interlocução de Turner com a psicanálise, pois há latência no símbolo, isto é, processos de pensamento inconscientes, coisas em processo de elaboração, aquilo sobre o que não se fala, mas que a observação da ação em seu contexto sugere. ${ }^{31}$ Turner (2005) fala no artigo de 1958 (o primeiro capítulo de FS) em psicologia profunda, e dialoga com o trabalho de diversos psicanalistas (entre eles Bettelheim e Jung). Explicita em RD como "todo o meu trabalho recente é quase inteiramente influenciado pelas perspectivas de Jung e de Freud [...]” (Turner, 1975, p. 29, tradução minha). Oring (1993), entretanto, já demonstrou de modo convincente o quanto a teoria do símbolo ritual de Turner deve diretamente às formulações de Freud acerca da simbolização onírica, que datam do começo do século XX (Freud, 1965, 1976).

Nessa interlocução, sobressai-se a distinção manifesto versus latente em que se baseia a ideia da estrutura tripartida do símbolo turneriano - em parte material, em parte semântica, em parte sociocultural. No símbolo, há múltiplos significados codificados que devem ser desvendados pela análise antropológica; subjacente a eles, encontram-se temas e valores culturais. Oring (1993, p. 279) demonstrou como essa elaboração pode ser diretamente derivada da distinção freudiana entre o conteúdo manifesto do sonho (objetos, ações, cenários retidos pela memória), os conteúdos latentes (os referentes inconscientes dos conteúdos manifestos) e os pensamentos inconscientes que motivaram o sonho (subsumidos na busca de realização do desejo). Ao mesmo tempo, trata-se de elaborar ferramentas analíticas para a decodificação da multiplicidade de sentidos abrangida na estrutura do símbolo e, para tanto, Turner apropria-se também dos mecanismos inconscientes de simbolização desvendados por Freud: condensação, deslocamento, sobredeterminação, e outras formas de transformação de elementos nos sonhos, responsáveis pelo que

\footnotetext{
31 A ideia de latente em Turner pode referir-se, por vezes, a ideias situacionalmente suprimidas (como os conflitos de ordem social que os ndembus sabem que existem, mas que expressamente ocultam na situação ritual (ver Oring, 1993, p. 279). Outras vezes, alude justamente a um efeito quase catártico da ação simbólica que torna manifestos sentimentos reprimidos, como é o caso da ambivalência das relações mãe/filha enfocada no ritual de iniciação feminina nkang'a, ou do comportamento agressivo e mesmo cruel dos adultos com os meninos no ritual de iniciação masculina, mukanda (Turner, 2005); ou ainda a raiva da autoridade ancestral deslocada para a morte de Kavula em chihamba (Turner, 1975).
}

Horizontes Antropológicos, Porto Alegre, ano 18, n. 37, p. 103-131, jan./jun. 2012 
Freud (1965, p. 311-374) denominou de “o trabalho do sonho". Turner os refraseia, entretanto, como "propriedades do símbolo" (Turner, 2005, p. 50-56): 1) os símbolos têm múltiplos referentes; 2) o símbolo promove a unificação desses sentidos diversos através de analogias, deslocamentos e cadeias associativas; 3) os símbolos condensam diferentes ações, objetos e representações; 4) os diferentes significados do símbolo tendem a se organizar em torno da polaridade orético versus ideológico. O polo orético ou sensorial do símbolo agrega as qualidades dos símbolos de condensação, tais como entendidos por Sapir (1999), ${ }^{32}$ isto é, saturados de emoção, cheios de associações inconscientes (Turner, 2005, p. 60, 61), como a dependência e a afeição ligadas ao aleitamento materno no exemplo da árvore leiteira. O polo ideológico ou normativo agregaria o simbolismo referencial, alusivo às normas e aos valores sociais e ideológicos conhecidos, como a harmonia e coesão idealizados pelas normas e valores da matrilinhagem na árvore leiteira vista como a "nossa bandeira" pelos ndembus (Turner, 2005, p. 65). ${ }^{33}$

O refraseamento dos mecanismos freudianos do trabalho dos sonhos como "propriedades dos símbolos", entretanto, ao mesmo tempo em que dota, diríamos hoje, o símbolo de grande poder de agência, tende a essencializar a noção de símbolo ritual em uma direção quase mística. Isso faz com que, no uso analítico desse conjunto de ideias, o símbolo ritual torne-se uma espécie de solução de compromisso entre duas tendências distintas imbricadas no pensamento de Turner: o forte interesse pela psicanálise e seu pendor religioso e metafísico que se ligaria também, mais tarde, à exaltação da performance como culminância de um fluxo vital. Vejamos.

O tema das relações simbólicas entre manifesto e latente encontrou ressonância não só no pensamento ndembu como no próprio indivíduo Victor Turner. O artigo de 1962 sobre chihamba (RD) enfocou especificamente esse tema. Em ndembu, nos diz Turner (1975, p. 15), o termo kusoloka significaria tornar visível, seja como: a) desvendamento do que antes estava escondido; e

\footnotetext{
${ }^{32}$ Sapir (1999, p. 321) elaborou, em ensaio seminal escrito em 1934, a distinção entre o simbolismo referencial, mais consciente e orientado por finalidades práticas e/ou cognitivas e o simbolismo de condensação, mais inconsciente e altamente emocional.

${ }^{33}$ A polaridade do símbolo promoveria a conversão do obrigatório no desejável já indicada por Durkheim. Na efervescência coletiva, nos diz Turner (2005, p. 61), "o símbolo ritual efetua um intercâmbio de qualidades entre os seus polos de significação - normas e valores de um lado se saturam de qualidade emocional e emoções básicas e grosseiras se enobrecem em contato com os valores sociais”.
}

Horizontes Antropológicos, Porto Alegre, ano 18, n. 37, p. 103-131, jan./jun. 2012 
esse nível de sentido remete à adivinhação e suas técnicas, que corresponde, para Turner, a um sistema abstrato de classificações, posto à parte do fluxo da experiência (Turner 1975, p. 16); ou como b) a manifestação daquilo que resiste à conceituação linguística. Turner traduz esse segundo sentido pela ideia de revelação: "Revelação é expor à vista em um cenário ritual e por meio de ações e veículos simbólicos tudo aquilo que não pode ser afirmado ou classificado verbalmente.” (Turner, 1975, p. 15, tradução minha). Chihamba seria, fundamentalmente, revelação.

Assim, enquanto a adivinhação é um modo de análise e um sistema taxonômico, a revelação é uma preensão (em inglês “prehension”) - a apreensão de alguma coisa feita pelos sentidos, ou o próprio ato de apreender oriundo da experiência vivida tomada como um todo. ${ }^{34} \mathrm{~A}$ estrutura social, nos diz Turner, é mascaramento, e chihamba, situado desde dentro da estrutura social, "aponta para a apreensão direta da realidade”. Esse sentido de totalidade, da possibilidade de uma apreensão integral, relacionado diretamente por Turner com a epifania cristã, seria continuamente restaurado nas performances do chihamba. Chihamba seria, por isso, a quintessência dos rituais de aflição. Nele, o cancelamento dos papéis de status um pelo outro - no sacrifício dos neófitos a Kavula pelos adeptos seniores, e no sacrifício de Kavula pelos neófitos - faz emergir com força o liminar como o lugar simbólico onde tudo é apenas ato e potencialidade pura, o zero, o vazio fecundo (Turner, 1975, p. 27). O símbolo, teoriza Victor Turner junto com Jung e com os ndembus, é como um clarão a conectar algo conhecido com o desconhecido, postulado entretanto como existente. Essa possibilidade se atualizaria no clímax dramático de chihamba, onde $\mathrm{o}$ ato de matar Kavula ergue a communitas aldeã africana ao poder metafísico (Turner, 1975, p. 27). Em sua abordagem de chihamba estaria, então, a busca de uma etnofilosofia, ou uma etnoteologia, ou por uma metalinguagem não verbal, a linguagem das formas e das ações simbólicas, que se configuram como tentativas de dizer o indizível.

Turner tomaria efetivamente esse aspecto do simbolismo de chihamba para si. Na introdução de RD, ele nos diz: "Muita gente vê como essencial em minha obra a dimensão conceitual no estudo do relacionamento entre processo social e ação simbólica. Mas chihamba, entre todos os rituais ndembus, por

${ }^{34}$ No Houaiss (2004), ato ou efeito de agarrar, pegar, segurar. 
sua ênfase simbólica central, mostrou-se avesso a essa abordagem.” (Turner, 1975, p. 19-20, tradução minha). Chihamba é, para Turner, um ritual paradigmático do pensamento imerso na materialidade de uma experiência corporal integral, e afetou-o profundamente como verdadeira revelação.

Vale a pena, nesse ponto, contrastar a abertura de seu primeiro artigo sobre os ndembus, LRC (Turner, 1953) com um trecho de sua introdução à RD (Turner, 1975). Em LRC, Turner (1953, p. 336, tradução minha) acreditava que seu estudo abordaria as danças e os rituais de um tempo passado: “O que espero fazer é reunir algumas impressões de como mesmo seres humanos analfabetos e iletrados na retaguarda da história foram capazes de criar uma estrutura religiosa harmoniosa e consistente.” Em RD, é um Turner (1975, p. 31, tradução minha) totalmente transformado quem nos confessa:

Eu não permaneci imune aos poderes simbólicos que invoquei na investigação de campo. Depois de muitos anos como um agnóstico e materialista monístico, eu aprendi com os ndembus que o ritual e seu simbolismo não são apenas meros epifenômenos ou disfarces para processos sociais e psicológicos mais profundos, mas possuem valor ontológico, de alguma forma relacionado com a condição do homem como uma espécie que evolui principalmente através de suas inovações culturais. Convenci-me de que a religião não é apenas um brinquedo da infância das raças, a ser descartada em um ponto nodal do desenvolvimento científico e tecnológico. Ela está no coração do problema humano. Decifrar as formas rituais e descobrir o que gera as ações simbólicas pode ser mais próximo de nosso crescimento cultural do que nós supusemos. Mas precisamos nos colocar de alguma maneira dentro dos processos religiosos para conhecê-los. Há que haver uma experiência de conversão.

Nesse mesmo texto, Turner (1975, p. 30) comenta, entretanto, como nos anos 1950, quando suas orientações teóricas eram durkheimianas e funcionalistas, "a majestade da simbologia freudiana do inconsciente emergiu para mim no papel de um paradigma crucial”. Preocupado com a distinção entre o psicanalítico e o propriamente cultural, ele prossegue, "mas o sentido freudiano da complexidade das formas e ações simbólicas, sua discriminação entre níveis de significado, e sua insistência na natureza polissêmica dos símbolos dominantes e das metáforas chave, tudo isso me estimulou a inquirir os processos rituais com os olhos abertos para a riqueza e sutileza dos fenômenos observados”. Chihamba é exemplar da solução de compromisso entre o metafísico e o metapsicológico.

Horizontes Antropológicos, Porto Alegre, ano 18, n. 37, p. 103-131, jan./jun. 2012 
Sperber (1974, p. 30, tradução minha) tomou a teoria do símbolo de Turner como paradigmática do que ele chamou de uma concepção criptológica do símbolo, segundo a qual "a interpretação do símbolo é objeto de um saber especial - ora acessível, ora reservado a experts e iniciados, ora esquecido nos dias de hoje, mas tendo existido no passado”. Ora, pergunta o autor, como fazer no caso da inexistência cultural de comentários sobre os símbolos? Sua resposta ressaltou o caráter limitado da teoria turneriana, que privilegiaria certas configurações simbólicas - como aquela característica dos ndembus, com seu gosto compartilhado por Turner pela exegese (Sperber, 1974, p. 60). Nessa mesma direção, Sperber arguiu que, afinal, a interpretação do símbolo em Turner não seria exatamente uma interpretação, mas antes uma extensão de seu desenvolvimento, mais uma possibilidade de sua significação. Vale observar que para a perspectiva hermenêutica, entretanto, esse fato não constitui um problema, sendo, ao contrário, seu fundamento. O ponto mais parcial da crítica de Sperber (1974, p. 35) a Turner parece-me residir, contudo, na ideia defendida por ele de que para a teoria criptológica, mesmo que não existisse a exegese nativa, a interpretação poderia lançar mão de um saber inconsciente universalmente compartilhado. Sperber (1974, p. 57-58) traz como exemplo desse simbolismo universal a interpretação da pistola com o pênis por Freud, visto como o grande formulador da ideia do simbolismo como um código inconsciente. Sperber possui uma visão estreita das formulações freudianas acerca da simbolização. Vale lembrar que o próprio Freud (1996, p. 224) reviu muitas vezes suas próprias opiniões e, com relação a esse ponto específico associou a interpretação dos símbolos oníricos à prática clínica, explicitando:

[...] é impossível compreender um sonho enquanto o sonhador não nos der as informações pertinentes. Pois suspeito que, no fundo, os senhores pensam que o método ideal de interpretação de sonhos consistiria em preencher a significação dos símbolos e que gostaria de prescindir da técnica de obter associações com os sonhos; e estou desejoso de dissuadi-los desse equívoco nocivo.

Como vimos, a leitura de Freud por Turner é também bem mais sofisticada do que afirma Sperber (1974). No entanto, o deslocamento empreendido por Turner da ideia freudiana de mecanismos psíquicos elementares de simbolização para a ideia de propriedades do símbolo acaba por essencializar, em alguma medida, a noção mesma de símbolo em Turner em uma direção 
metafísica. Em especial, a associação da brancura de chihamba às brancuras de Moby Dick, do cordeiro de Deus, de imagens do paraíso de Dante (Turner, 1975) aproxima-se, de fato, da ideia da brancura como um código inconsciente de significação universal.

Turner reconheceu a força dos paradigmas psicanalíticos em um momento de sua obra, mas isso tudo não dava conta dos aspectos performativos e dramáticos dos rituais: "Não apenas os próprios rituais, mas os processos sociais e culturais nos quais eles estão imbricados, me levaram também à literatura e aos críticos dramatúrgicos [...] pois os rituais são momentos em um infindável fluxo de relações em desenvolvimento e em declínio entre os indivíduos e os grupos.” (Turner, 1975, p. 30, tradução minha).

Creio que a gravidade mística que Turner terminou por atribuir ao símbolo nos faz quase esquecer que Kavula, manifestação espiritual central em chihamba, é também performance - um artefato, manipulado pelos adeptos seniores que atuam como palhaços! Ao mesmo tempo, Kavula revela, qual um raio, o quanto a ideia de performance já ocupava, nos anos 1950 e 1960, lugar central em seu pensamento. No curso da obra de Turner, a teoria semântica do símbolo, e com ela seu interesse pela dimensão propriamente inconsciente da ação simbólica, se dissociaria da noção de performance, que seguiria seu próprio caminho, o qual não deixaria, entretanto, de tomar em muitos momentos contornos místicos.

\section{Referências}

ALEXANDER, B. C. Victor Turner revisited: ritual as social change. Atlanta: Scholars Press, 1991.

BABCOCK, B. A. Obituary: Victor W. Turner (1920-1983). The Journal of American Folklore, v. 97, n. 386, p. 461-464, Oct./Dec. 1984.

CAVALCANTI, M. L. V. de C. Carnaval carioca: dos bastidores ao desfile. Rio de Janeiro: Ed. UFRJ, 2006.

CAVALCANTI, M. L. V. de C. Drama social, notas sobre um tema de Victor Turner. Cadernos de Campo, ano 16, n. 16, p. 127-138, dez. 2007. 
CLIFFORD, J. Sobre a alegoria etnográfica. In: GONÇALVES, J. R. (Org.). A experiência etnográfica: antropologia e literatura no século XX. Rio de Janeiro: EdUFRJ, 1998. p. 63-99.

DAMATTA, R. Ensaios de antropologia estrutural. Petrópolis: Vozes, 1973.

DAMATTA, R. Carnavais, malandros e heróis. Rio de Janeiro: Zahar Editor, 1979.

DAMATTA, R. Individualidade e liminaridade: considerações sobre os ritos de passagem e a modernidade. Mana: Estudos de Antropologia Social, Rio de Janeiro, v. 6, n. 1, p. 7-29, abr. 2000.

DAMATTA, R. Conversa com Roberto DaMatta. Entrevista por Carmen Rial e Lia Zanota Machado. In: REUNIÃO BRASILEIRA DE ANTROPOLOGIA, 25., 2006, Goiânia. Conferências e diálogos: saberes e práticas antropológicas. Goiânia: Nova Letra, 2007. p. 259-281.

DAWSEY, J. Victor Turner e a antropologia da experiência. Cadernos de Campo, ano 14, n. 13, p. 163-176, 2005.

DE BOECK, F.; DEVISCH, R. Ndembu, Lunda and Yaka divination compared: from representation and social engeneering to embodiment and worldmaking. Journal des Religions Africaines, v. 24, n. 2, p. 1-23, 1994.

DEFLEM, M. Ritual, anti-structure, and religion: a discussion of Victor Turner's Processual Symbolic Analysis. Journal for the Scientific Study of Religion, v. 30, n. 1, p. 1-25, 1991.

DURKHEIM, É. As formas elementares da vida religiosa. São Paulo: Martins Fontes, 1996.

EVANS-PRITCHARD, E. E. The divine Kingship of the Shilluk of the Nilotic Sudan. Cambridge: Cambridge University Press, 1948.

EVANS-PRITCHARD, E. E. Nuer religion. Oxford: Oxford University Press, 1956. 
ENGELKE, M. The endless conversation: Fieldwork, writing, and the marriage of Victor and Edith Turner. In: HANDLER, R. (Org.). Significant others: interpersonal and professional commitments in anthropology. Winsconsin: The University of Wisconsin Press, 2004. p. 6-49.

ENGELKE, M. An interview with Edith Turner. In: ST. JOHN, G. (Ed.). Victor Turner and contemporary cultural performance. New York: Berghahn Books, 2008. p. 275-276.

FORTES, M. The dynamics of clanship among the Tallensi. London: Oxford University Press, 1945.

FORTES, M. The web of clanship among the Tallensi. London: Oxford University Press, 1949.

FORTES, M. Religion, morality and the person: esays on Tallensi religion. Cambridge: Cambridge University Press, 1987.

FORTES, M.; EVANS-PRITCHARD, E. E. (Ed.). African political systems. London: Oxford University Press, 1940.

FREUD, S. The interpretation of dreams. New York: Avon Books, 1965.

FREUD, S. Sonhos. In: FREUD, S. Conferências introdutórias sobre a psicanálise: partes I e II. Rio de Janeiro: Imago, 1976. p. 105-285. (Edição Standard Brasileira das Obras Psicológicas Completas de Sigmund Freud, v. 15).

GEERTZ, C. O saber local. Petrópolis: Vozes, 1997.

GLUCKMAN, M. Les rites de passage. In: GLUCKMAN, M. (Org.). Essays on the ritual of social relations. Manchester: Manchester University Press, 1962. p. 1-52.

GLUCKMAN, M. Order and rebellion in tribal Africa. London: Cohen \& West, 1963.

GLUCKMAN, M. Ritos de rebelião. Brasília: Universidade de Brasília, 1974. (Cadernos de Antropologia, n. 4). 
GLUCKMAN, M. O material etnográfico na antropologia social inglesa. In: ZALUAR, A. (Org.) Desvendando máscaras sociais. Rio de Janeiro: Livraria Francisco Alves Editora, 1990. p. 64-76.

GLUCKMAN, M. Preface. In: TURNER, V. Schism and continuity in na African society. Manchester: Manchester University Press, 1996. p. XV-XX.

GONÇALVES, J. R. S. Apresentação. In: CLIFFORD, J. A experiência etnográfica: antropologia e literatura no século XX. Rio de Janeiro: EdUFRJ, 1998. p. 7-16.

GRIMES, R. L. Victor Turner's definition, theory and sense of ritual. In: ASHLEY, K. (Ed.). Victor Turner and the construction of cultural criticism: between literature and anthropology. Indiana: Indiana University Press, 1990. p. 141-146.

HOUAISS, A. Dicionário Houaiss da língua portuguesa. Rio de Janeiro: Objetiva, 2004.

KUPER, H. A ritual of kingship among the Swazi. Africa: Journal of the International African Institute, v. 14, n. 5, p. 230-257, Jan. 1944.

LA FONTAINE, J. (Ed.). The interpretation of ritual: essays in honour of A. I. Richards. London: Tavistock Publications, 1972.

LENCLUD, G. Turner, Victor Witte. In: BONTE, P.; IZARD, M. (Ed.). Dictionnaire de l'ethnologie et de l'anthropologie. Paris: Presses Universitaires de France, 1991. p. 721-722.

LEOPOLDI, J. S. Escola de samba, ritual e sociedade. Petrópolis: Vozes, 1978.

LE ROY LADURIE, E. Le carnaval des romans. Paris: Gallimard, 1979.

LONSDALE, S. H. Dance and ritual play in Greek religion. Baltimore: The Johns Hopkins University Press, 1993.

MAGGIE, Y. Guerra de orixá: um estudo de ritual e conflito. Rio de Janeiro: Zahar Editor, 2001. 
MALINOWSKI, B. Argonautas do Pacífico Ocidental. São Paulo: Abril Cultural, 1976.

MANNING, F. E. Victor Turner's career and publication. In: ASHLEY, K. (Ed.). Victor Turner and the construction of cultural criticism: between literature and anthropology. Indiana: Indiana University Press, 1990. p. 170-177.

ORING, E. Victor Turner, Sigmund Freud and the return of the repressed. Ethos, v. 21, n. 3, p. 273-294, Sept. 1993.

PEIRANO, M. As árvores Ndembu, uma re-análise. In: ANUÁRIO ANTROPOLÓGICO DE 1990. Rio de Janeiro: Tempo Brasileiro, 1993. p. 9-64.

RICHARDS, A. Chisungu: a girl's initiation ceremony among the Bemba of Zambia. London: Routledge, 1982.

SAHLINS, M. Culture and practical reason. Chicago: The University of Chicago Press, 1976.

SAPIR, E. Symbolism. In: DARNELL, R.; IRVINE, J. (Ed.). The collected works of Edward Sapir. Berlin: Mouton de Gruyter, 1999. v. 3, p. 319-325.

SCHECHNER, R. Preface: Victor Turner's last adventure. In: TURNER, V. Anthropology of performance. New York: PAJ, 1987. p. 7-20.

SCHUMAKER, L. The director as significant other. Max Gluckman and Team Fieldwork at the Rhodes-Livingstone Institute. In: HANDLER, R. (Org). Significant others: interpersonal and professional commitments in anthropology. Winsconsin: The University of Wisconsin Press, 2004. p. 91-130.

SILVA, R. A. Entre “artes” e “ciências”: as noções de performance e drama no campo das ciências sociais. Horizontes Antropológicos, ano 11, n. 24, p. 35-65, 2005.

SPERBER, D. Le symbolisme en général. Paris: Hermann, 1974.

ST. JOHN, G. Introduction. In: St. JOHN, G. (Ed.). Victor Turner and contemporary cultural performance. New York: Berghahn Books, 2008. p. 1-37. 
TURNER, E. The spirit and the drum: a memoir of Africa. Tucson: Arizona University Press, 1987.

TURNER, V. Lunda rites and ceremonies. The Occasional Papers of the Rhodes-Livingstone Museum, University of Zambia by Manchester University Press, n. 10, p. 335-388, 1953.

TURNER, V. Three symbols of passage in Ndembu circumcision ritual. An interpretation. In: GLUCKMAN, M. (Ed.). Essays on the ritual of social relations. Manchester: Manchester University Press, 1962. p. 124-173.

TURNER, V. The drums of affliction: a study of religious processes among the Ndembu of Zambia. Oxford: Oxford University Press, 1968.

TURNER, V. Symbols in African Ritual. Science, n. 179, p. 1100-1105, March 16, 1973.

TURNER, V. Dramas fields and metaphors. Ithaca: Cornell University Press, 1974a.

TURNER, V. O processo ritual: estrutura e anti-estrutura. Petrópolis: Vozes, 1974b.

TURNER, V. Revelation and divination in Ndembu ritual. Ithaca: Cornell University Press, 1975.

TURNER, V. From ritual to theatre: the human seriousness of play. New York: PAJ, 1982.

TURNER, V. On the edge of the bush: the anthropology of experience. Tucson: Arizona University Press, 1985.

TURNER, V. Dewey, Dilthey and drama: an essay in the anthropology of experience. In: TURNER, V.; BRUNER, E. M. (Ed.). The anthropology of experience. Urbana: University of Illinois Press, 1986. p. 33-44.

TURNER, V. The anthropology of performance. New York: PAJ, 1987.

TURNER, V. Schism and continuity in an African society. Manchester: Manchester University Press, 1996.

TURNER, V. Floresta de símbolos: aspectos do ritual Ndembu. Niterói: EdUFF, 2005. 
TURNER, V. Drama, campos e metáforas. Niterói: EdUFF, 2008.

TURNER, V.; TURNER, E. Image and pilgrimage in Christian culture. New York: Columbia University Press, 1978.

VAN GENNEP, A. The rites of passage. Chicago: Chicago University Press, 1960.

VOGEL, A.; MELLO, M. A.; BARROS, J. F. P. Galinha d'Angola: iniciação e identidade na cultura brasileira. Rio de Janeiro: Pallas, 1998.

WEBER, D. From limen to border: a meditation on the legacy of Victor Turner. American Cultural Studies: American Quarterly, v. 47, n. 3, p. 525-536, 1995.

WILSON, M. Nyakyusa ritual and symbolism. American Anthropologist: New Series, v. 56, n. 2, p. 228-241, Part 1, Apr. 1954.

WILSON, M. Rituals of kinship among the Nyakusa. Oxford: Oxford University Press, 1957.

Recebido em: 30/08/2011

Aprovado em: 10/10/2011 